\title{
Determinants of postinfarction remodeling affect outcome and left ventricular geometry after surgical treatment of ischemic cardiomyopathy
}

\author{
Marco Cirillo, MD \\ Andrea Amaducci, MD ${ }^{\mathrm{b}}$ \\ Federico Brunelli, MD ${ }^{\mathrm{a}}$ \\ Margherita Dalla Tomba, MD \\ Piervirgilio Parrella ${ }^{\mathrm{c}}$ \\ Giordano Tasca, MD ${ }^{a}$ \\ Giovanni Troise, $\mathrm{MD}^{\mathrm{a}}$ \\ Eugenio Quaini, MD
}

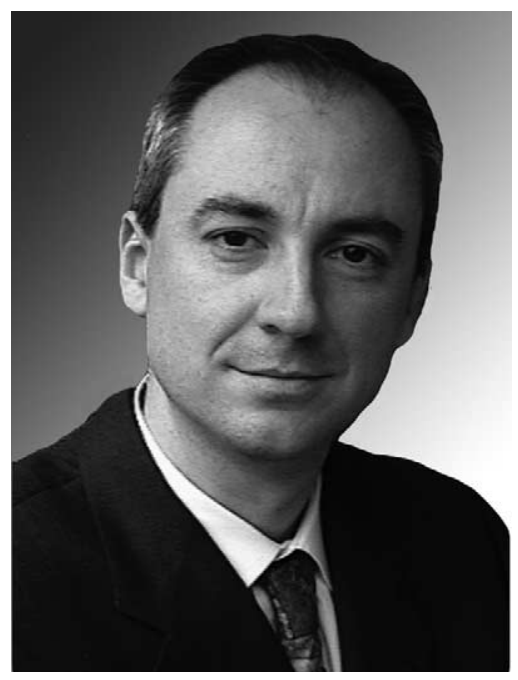

Dr Cirillo
Objective: To identify the effects of the time between myocardial infarction and surgery, the site of infarction, mitral involvement on ventricular geometry, and clinical outcome in the treatment of ischemic cardiomyopathy in patients with heart failure.

Methods: Sixty-nine consecutive patients with ischemic cardiomyopathy, indexed end-systolic volume $\geq 50 \mathrm{~mL} / \mathrm{m}^{2}$, ejection fraction $\leq 35 \%$, and heart failure underwent surgery $81.9 \pm 100.8$ months after myocardial infarction, using different techniques of ventricular restoration. Thirteen geometric parameters were studied pre- and postoperatively. Paired and unpaired $t$ tests and general linear model for multivariate analysis were used to analyze subgroups. Logistic regression and Kaplan-Meier survival curves with pairwise log-rank were used to correlate covariates to clinical outcome.

Results: Longer time to surgery and posterior necrosis linearly correlated with higher left ventricular volumes $\left(r^{2}=.66\right)$ and diameters $\left(r^{2}=.40\right)$. High grade of mitral regurgitation was always present in posterior infarctions. Hospital mortality was $4.3 \%$. Complicated postoperative course was predicted by mitral surgery ( $P=$ $.004)$ and longer time to surgery $(P=.04)$. Survival was significantly lower in the posterior infarction $(P=.0002)$ and mitral surgery $(P=.001)$ subgroups. At a mean follow-up of $1.9 \pm 1.3$ years, functional status and geometrical restoration are influenced by the studied covariates.

Conclusions: Longer time to surgery after myocardial infarction, its posterior location, and significant mitral regurgitation can affect left ventricular remodeling, surgical restoration, and clinical outcome in patients with ischemic cardiomyopathy.

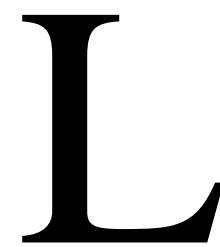

eft ventricular (LV) remodeling after single or multiple myocardial infarctions (MIs) is a major problem affecting the surgical approach to ischemic heart disease. Cardiac remodeling is an endless, timedependent process that involves profound changes in cellular and extracellular cardiac structure and affects heart geometry and function. The development of these alterations has been studied in vivo ${ }^{1}$ and in clinical series.

Infarction scar healing is related to the different structural and anatomic layers of the myocardium, and the preexisting extracellular matrix plays an important role in the organization of scar collagen. ${ }^{2}$ The 3 parameters linked to the evolution and 
development of remodeling are time ${ }^{3-5}$ the site of ischemia, ${ }^{6}$ and mitral regurgitation (MR $)^{7}$ the different overlapping of which contribute to the speed of symptom onset, LV dilation, and the geometric distortion of the LV cavity.

Restoring the shape of the left ventricle (ie, reestablishing near-normal geometry) has recently been stressed as a key means of treating or avoiding congestive heart failure. ${ }^{8}$ It has also been found that the indexed end-systolic volume of the left ventricle (iESV) can be used as a prognostic factor insofar as a value of more than $45 \mathrm{~mL} / \mathrm{m}^{2}$ often leads to clinical heart failure, ${ }^{9}$ and a resting iESV of more than 60 $\mathrm{mL} / \mathrm{m}^{2}$ is a threshold that is probably associated with subsequent cardiac mortality. ${ }^{10}$ Preoperative end-systolic and end-diastolic left ventricular volumes both correlate with outcome $^{11,12}$ : a patient with a preoperative iESV of less than $100 \mathrm{~mL} / \mathrm{m}^{2}$ is much more likely to survive than one with a higher value, and a preoperative indexed end-diastolic volume of more than $160 \mathrm{~mL} / \mathrm{m}^{2}$ more frequently leads to a poorer outcome.

The aim of this study was to identify the ways in which the time between MI and surgery, the location of the MI, and the presence of mitral involvement affect ventricular geometry and influence clinical outcome in a series of patients surgically treated for ischemic heart failure.

\section{Methods}

\section{Patients}

Sixty-nine consecutive patients with ischemic cardiomyopathy defined according to Burch and colleagues ${ }^{13}$ underwent surgical treatment between September 1997 and November 2002. The study population had experienced 1 or more episode of MI with segmental LV wall motion abnormalities and had an $\mathrm{EESV}$ of $\geq 50$ $\mathrm{mL} / \mathrm{m}^{2}$ and an ejection fraction (EF) of $\leq 35 \%$; heart failure was the predominant clinical manifestation. Their clinical characteristics are summarized in Table 1.

\section{Definitions}

All clinical definitions were taken from the 1998 data collection form of the Society of Thoracic Surgeons National Cardiac Surgery Database.

MI surgery time interval: From the first episode of MI (presumed to be responsible for the subsequent cardiomyopathy) to surgery.

MI recurrences: In the same or different sites.

Anterior MI: All anterior, anterolateral, and anteroapical locations.

Posterior MI: All inferior, basal, posterior, and posterolateral locations.

Complicated postoperative course: At least 1 of the following: the need for inotropes or an intra-aortic balloon pump (IABP), renal failure treated by means of continuous veno-venous ultrafiltration, respiratory insufficiency, perioperative MI.

\section{Echocardiographic Measurements}

To obtain homogeneous and consistent echocardiographic data, all of the pre- and postoperative echocardiographic studies were per-
TABLE 1. Patient characteristics

\begin{tabular}{lc}
\hline Men/women & $54 / 15$ \\
Age (y) & $65.6 \pm 8.8(40-82)$ \\
Urgency/emergency & $13(19.4 \%)$ \\
Presence of MR & $54(91.5 \%)$ \\
MR $\geq$ grade 2 & $24(34.7 \%)$ \\
MR $\geq$ grade 2 in anterior Mls & $11(19.6 \%)$ \\
MR $\geq$ grade 2 in posterior Mls & $13(100 \%)$ \\
Mean NYHA class & $2.5 \pm 1$ \\
Patients in NYHA class IV & $16(23.1 \%)$ \\
Three-vessel coronary disease & $29(42.1 \%)$ \\
One-vessel coronary disease & $16(23.1 \%)$ \\
Mean time interval to surgery (mo) & $81.9 \pm 100.8(0.3-403.5)$ \\
Anterior myocardial infarction & 56 \\
$\quad$ Mean time to surgery & $65.1 \pm 84.2$ \\
Posterior myocardial infarction & 13 \\
$\quad$ Mean time to surgery & $154 \pm 134.3$ \\
Recurrences of MI & 7 (single), 2 (double) \\
\hline
\end{tabular}

MR, Mitral regurgitation; MI, myocardial infarction; NYHA, New York Heart Association.

formed by the same echocardiographer using an Acuson Sequoia 512 (Acuson Corporation, Mountain View, Calif) equipped with 2.5- to 3.5-MHz transducers. The preoperative examinations were performed 0 to 7 days before surgery; the postoperative echocardiograms used for this study were performed at least 6 months after the operation.

MR was quantified by means of Doppler analysis using a 4-point scale.

The evaluated LV geometric and functional parameters are described in Appendix 1.

\section{Surgical Details}

All of the operations were performed by means of a median sternotomy using a mild hypothermic $\left(33^{\circ} \mathrm{C}\right)$ cardiopulmonary bypass, aortic crossclamp, intermittent cold blood cardioplegia, and warm reperfusate.

The surgical techniques used for LV restoration were: (1) the reconstruction of anterior LV akinesia/dyskinesia by means of the endoventricular circular patch plasty described by Dor and colleagues ${ }^{14}$ or modified versions of the same (without the internal patch or using linear closure when the residual postreduction area was small); (2) the treatment of mitral valve regurgitation by means of annuloplasty or mitral valve replacement; or (3) a combination of the 2 treatments.

After the completion of surgical restoration, all patients received coronary artery bypass grafts to achieve complete revascularization.

The pre- and postoperative indications for the use of an IABP were prophylactic support or a cardiac index of $<2.0 \mathrm{~L} / \mathrm{min} / \mathrm{m}^{2}$ despite the administration of inotropes.

\section{Follow-up}

After the 3-month clinical follow-up examination, the patients were interviewed every year by telephone. The survivors were invited to undergo an echocardiographic control and clinical assessment at our hospital at least 6 months after surgery. 
TABLE 2. Comparison of geometric and functional echocardiographic parameters in patients with previous anterior versus posterior myocardial infarction

\begin{tabular}{|c|c|c|c|c|}
\hline \multirow[b]{3}{*}{ Parameters } & \multicolumn{4}{|c|}{ MI location } \\
\hline & \multicolumn{2}{|c|}{ Preoperative } & \multicolumn{2}{|c|}{ Postoperative } \\
\hline & $\begin{array}{l}\text { Anterior } \\
(n=56)\end{array}$ & $\begin{array}{l}\text { Posterior } \\
(\mathrm{n}=13)\end{array}$ & $\begin{array}{l}\text { Anterior } \\
(\mathrm{n}=55)\end{array}$ & $\begin{array}{l}\text { Posterior } \\
(\mathrm{n}=10)\end{array}$ \\
\hline End-systolic diameter & $46.2 \pm 10.3$ & $51 \pm 8.7$ & $41.4 \pm 7.1 \dagger$ & $48.3 \pm 8.0^{*}$ \\
\hline $\begin{array}{l}\text { End-diastolic diameter } \\
\text { Eccentricity index }\end{array}$ & & $59.8 \pm 9.3$ \\
\hline Systolic & $0.82 \pm 0.09$ & $0.75 \pm 0.07^{*}$ & $0.73 \pm 0.13 \dagger$ & $0.72 \pm 0.14$ \\
\hline Diastolic & $0.74 \pm 0.09$ & $0.66 \pm 0.08^{*}$ & $0.56 \pm 0.17 \dagger$ & $0.64 \pm 0.18$ \\
\hline \multicolumn{5}{|l|}{ Longitudinal length } \\
\hline Systolic & $84.7 \pm 12.9$ & $79.1 \pm 11.5$ & $63.4 \pm 8.5 \dagger$ & $73.6 \pm 12.3^{*}$ \\
\hline Diastolic & $93.4 \pm 12.1$ & $89.3 \pm 7.9$ & $71.7 \pm 7.7 \dagger$ & $83.1 \pm 8.6^{*}$ \\
\hline End-diastolic volume & $183.9 \pm 69.3$ & $199.5 \pm 74.8$ & $117.1 \pm 33.4 \dagger$ & $149.6 \pm 41.2^{*}, \dagger$ \\
\hline End-diastolic volume index & $101.1 \pm 38$ & $105.5 \pm 40.2$ & $64.4 \pm 16.9 \dagger$ & $78.2 \pm 17.8^{*}, \dagger$ \\
\hline End-systolic volume & $120.6 \pm 53.8$ & $119.1 \pm 54.4$ & $64.6 \pm 19.8 \dagger$ & $91.1 \pm 32.5^{*}$ \\
\hline End-systolic volume index & $66.5 \pm 30.3$ & $62.8 \pm 28.5$ & $35.5 \pm 10.2 \dagger$ & $47.4 \pm 14.4^{*}$ \\
\hline Ejection fraction & $31.9 \pm 4.8$ & $33.7 \pm 2.3^{*}$ & $46.6 \pm 6.5 \dagger$ & $37.3 \pm 8.9^{*}$ \\
\hline Wall motion score index & $2.07 \pm 0.34$ & $1.91 \pm 0.40$ & $1.68 \pm 0.23 \dagger$ & $1.67 \pm 0.35$ \\
\hline$\%$ of akinesia & $34.8 \pm 8.5$ & $32.8 \pm 17.2$ & $27.8 \pm 5.2 \dagger$ & $31.6 \pm 13.3$ \\
\hline
\end{tabular}

MI, Myocardial infarction. Parameters are defined in the Appendix. ${ }^{*}$ Significance between the groups, anterior versus posterior location.

tSignificance within the group, preoperative versus postoperative.

\section{Statistical Analysis}

The clinical, echocardiographic, operative, and outcome data were prospectively collected in our institutional database and statistically analyzed using SPSS 9.0 software (SPSS Inc, Chicago, Ill). The continuous variables are expressed as mean values \pm standard deviation. The two-tailed paired $t$ test was used to compare the preand postoperative data and the unpaired $t$ test to compare the groups. The continuous variables were compared using linear regression analysis and the dichotomous variables by means of binary logistic regression (ENTER stepwise method). The multivariate analysis was based on the general linear model and tested the effects of 4 covariates (anterior/posterior MI, the MI surgery time interval, grade 2 or greater MR, number of recurrent MIs) on all of the preoperative LV geometric and functional parameters. A postoperative complicated course was considered a dichotomous variable (no/yes $=0 / 1$ ). Kaplan-Meier actuarial survival was calculated for the whole population and the subgroups, and betweengroup survival was analyzed using the pairwise log-rank test.

\section{Results}

The site of MI was anterior in 56 and posterior in 13 patients. Seven patients had experienced a single recurrence (6 in the same site as the first and 1 in a different region), and 2 patients had experienced a double recurrence in the same site as the first episode. The mean MI surgery interval in the population as a whole was $81.9 \pm 100.8$ months (range 0.3-403.5); the median interval was 60 months. The mean MI surgery interval was significantly different $(P=$ .03) between the patients with anterior and posterior MI $(65.1 \pm 84.2$ vs $154 \pm 134.3$ months $)$. Eleven patients with anterior MI (19.6\%) and 13 (100\%) with posterior MI had MR grade 2 or greater, requiring mitral surgery $(P<.0001)$.

\section{Preoperative LV Geometric and Functional Parameters}

The patients with a posterior MI had significantly lower systolic $(0.75 \pm 0.007$ vs $0.82 \pm 0.09 ; P=.01)$ and diastolic $(0.66 \pm 0.08$ vs $0.74 \pm 0.09 ; P=.007)$ eccentricity index than those with anterior MI. They also had a higher EF $(33.7 \pm 2.3$ vs $31.9 \pm 4.8 ; P=.04$; Table 2$)$.

At the median MI surgery time interval of 5 years $(60$ months), the population was divided into approximately halves ( 39 before and 30 after 60 months). The patients with an MI surgery time interval of $>60$ months had more dilated (end-systolic diameter $=50.8 \pm 10.3$ vs $44.3 \pm 9.2$; $P=.008$; end-diastolic diameter $=65.4 \pm 8.7$ vs $58.7 \pm$ $8.5 ; P=.002$ ) and more spherical ventricles (diastolic eccentricity index $=0.69 \pm 0.11$ vs $0.75 \pm 0.07 ; P=.01$; Table 3).

Linear regression analysis of the posterior MI group revealed a significant correlation between the MI surgery time interval (continuous variable) and iESV $\left(r^{2}=.40\right)$, end-diastolic $\left(r^{2}=.65\right)$, and end-systolic $\left(r^{2}=.66\right)$ diameters (Figure 1).

General linear model multivariate analysis revealed a significant correlation between the MI surgery time interval and a longer systolic $\left(P=.02, r^{2}=.18\right)$ and diastolic $(P=$ $\left..01, r^{2}=.17\right)$ longitudinal length, a worse $\mathrm{EF}\left(P=.04, r^{2}\right.$ 
TABLE 3. Comparison of geometric and functional echocardiographic parameters in patients with an MI surgery time interval $<60$ months versus $>60$ months

\begin{tabular}{|c|c|c|c|c|}
\hline \multirow[b]{3}{*}{ Parameters } & \multicolumn{4}{|c|}{ MI surgery time interval } \\
\hline & \multicolumn{2}{|c|}{ Preoperative } & \multicolumn{2}{|c|}{ Postoperative } \\
\hline & $\begin{array}{l}<60 \text { months } \\
(\mathrm{n}=39)\end{array}$ & $\begin{array}{l}>60 \text { months } \\
(\mathrm{n}=30)\end{array}$ & $\begin{array}{l}<60 \text { months } \\
(n=38)\end{array}$ & $\begin{array}{l}>60 \text { months } \\
(n=27)\end{array}$ \\
\hline End-systolic diameter & $44.3 \pm 9.2$ & $50.8 \pm 10.3^{*}$ & $39.6 \pm 6.6 \dagger$ & $46.8 \pm 7.2^{*}$ \\
\hline $\begin{array}{l}\text { End-diastolic diameter } \\
\text { Eccentricity index }\end{array}$ & $58.7 \pm 8.5$ & $65.4 \pm 8.7^{*}$ & $54.1 \pm 6.1 \dagger$ & $61.9 \pm 6.6^{*}$ \\
\hline Systolic & $0.82 \pm 0.08$ & $0.78 \pm 0.09$ & $0.73 \pm 0.13 \dagger$ & $0.71 \pm 0.13 \dagger$ \\
\hline Diastolic & $0.75 \pm 0.07$ & $0.69 \pm 0.11^{*}$ & $0.60 \pm 0.16 \dagger$ & $0.54 \pm 0.19 \dagger$ \\
\hline \multicolumn{5}{|l|}{ Longitudinal length } \\
\hline Systolic & $81.6 \pm 14.1$ & $86.3 \pm 10.4$ & $61.2 \pm 8.0 \dagger$ & $70.7 \pm 10.1^{*}, \dagger$ \\
\hline Diastolic & $91.6 \pm 12.7$ & $94.0 \pm 9.8$ & $71.0 \pm 7.8 \dagger$ & $77.6 \pm 9.1^{*}, \dagger$ \\
\hline End-diastolic volume & $176.2 \pm 74.1$ & $200.6 \pm 62.9$ & $106.7 \pm 30.1 \dagger$ & $144.9 \pm 34.2^{*}, \dagger$ \\
\hline End-diastolic volume index & $97.9 \pm 40.9$ & $107.3 \pm 34.0$ & $59.4 \pm 15.7 \dagger$ & $76.8 \pm 15.6^{*}, \dagger$ \\
\hline End-systolic volume & $114.3 \pm 54.9$ & $128.2 \pm 51.6$ & $60.0 \pm 16.9 \dagger$ & $82.1 \pm 27.8^{*}, \dagger$ \\
\hline End-systolic volume index & $63.7 \pm 31.6$ & $68.5 \pm 27.4$ & $33.3 \pm 8.8 \dagger$ & $43.5 \pm 13.1^{*}, \dagger$ \\
\hline Ejection fraction & $32.2 \pm 4.5$ & $32.3 \pm 4.4$ & $46.6 \pm 6.7 \dagger$ & $42.6 \pm 8.6^{*}, \dagger$ \\
\hline Wall motion score index & $2.0 \pm 0.34$ & $2.1 \pm 0.36$ & $1.61 \pm 0.22 \dagger$ & $1.76 \pm 0.26^{*}, \dagger$ \\
\hline$\%$ of akinesia & $33.7 \pm 8.4$ & $35.4 \pm 12.9$ & $26.0 \pm 5.1 \dagger$ & $31.9 \pm 8.8^{*}$ \\
\hline
\end{tabular}

$M I$, Myocardial infarction. Parameters are defined in the Appendix.

*Significance between the groups, $<60$ months versus $>60$ months time interval.

tSignificance within the group, preoperative versus postoperative.

$=.19)$, a greater wall motion score index (WMSI; $P=.02$, $\left.r^{2}=.17\right)$, and a higher percentage of akinesia $(P<.0001$, $\left.r^{2}=.48\right)$. Significant correlations were also identified between posterior MI and a lower systolic eccentricity index $\left(P=.007, r^{2}=.29\right)$, a shorter systolic longitudinal length $\left(P=.01, r^{2}=.18\right)$, and a higher $\mathrm{EF}\left(P=.04, r^{2}=.19\right)$.

\section{Surgery}

Two patients received a preoperative IABP ( 1 for prophylaxis and 1 because of cardiogenic shock). Isolated reconstruction of left ventricle was performed in 45 patients (65.2\%), 37 with internal patch and 8 with linear overlapped suture of ventriculotomy. Isolated mitral surgery was performed in 12 patients (17.3\%): 9 patients received a complete ring annuloplasty ( 1 size 28,7 size 30,1 size 32 ), 2 patients a posterior ring annuloplasty (size 30 ), and 1 patient had mitral valve replacement with pericardial 25 prosthesis. Twelve patients had a combined procedure (17.3\%): 8 patients had a ventricular patch with annuloplasty, complete ring in 7 ( 1 size 28,3 size 30,3 size 32 ) and posterior ring in 1 patient (size 30), and 1 patient had ventricular patch with mitral valve replacement (mechanical prosthesis 27); 3 patients with linear suture had combined mitral procedure, 2 complete ring annuloplasty (size 30 and size 32 ) and 1 mitral valve replacement with pericardial 27 prosthesis.

As regards mitral surgery, the valve was repaired whenever possible. When replacement was required, posterior leaflet chordal attachments were preserved in all patients with preservation of anterior leaflet chordae in 2 .
All patients underwent complete coronary revascularization with $2.4 \pm 1$ grafts per patient (range 1-4). An IABP was postoperatively inserted in 10 patients ( 8 for prophylactic and 2 because of postcardiotomy low cardiac output syndrome).

\section{Outcome}

Hospital mortality was $4.3 \%$ ( 3 patients): 1 death in the mitral surgery group $(8.3 \% ; P=.4$ vs the isolated ventricular reconstruction group) and 2 in the combined surgery group $(16.6 \% ; P=.03$ vs the isolated ventricular reconstruction group), all due to cardiogenic multiorgan failure.

The mean length of stay in the intensive care unit was 5.4 \pm 9.5 days (range 1-70) and the total hospital stay was 10.3 \pm 9.4 days (range $5-80$ ).

Eighteen patients experienced a nonfatal complicated postoperative course: 9 in the isolated ventricular reconstruction group (20\%), 4 in the isolated mitral surgery group (33.3\%; $P=.4$ vs the isolated ventricular reconstruction group), and 5 in the combined surgery group $(41.6 \% ; P=$ .03 vs the isolated ventricular reconstruction group). Binary logistic regression analysis identified mitral surgery $(P=$ $.004)$ and the MI surgery time interval $(P=.04)$ as significant predictors of a complicated postoperative course.

The mean follow-up (98.5\% complete) was $1.9 \pm 1.3$ years (range 0.6-5.1). There were no readmissions due to cardiac causes.

Late mortality was $7.5 \%$ (5/66 discharged patients): 2 cardiac-related deaths 40 days and 15 months after the 
A

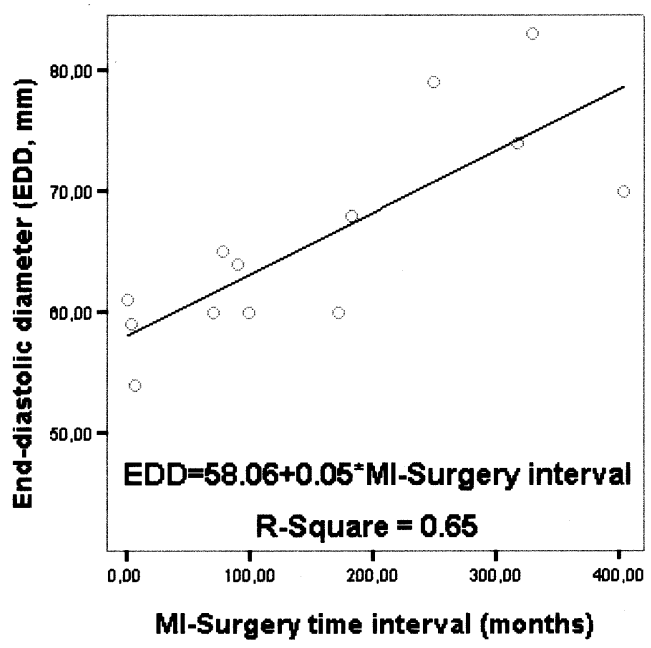

C

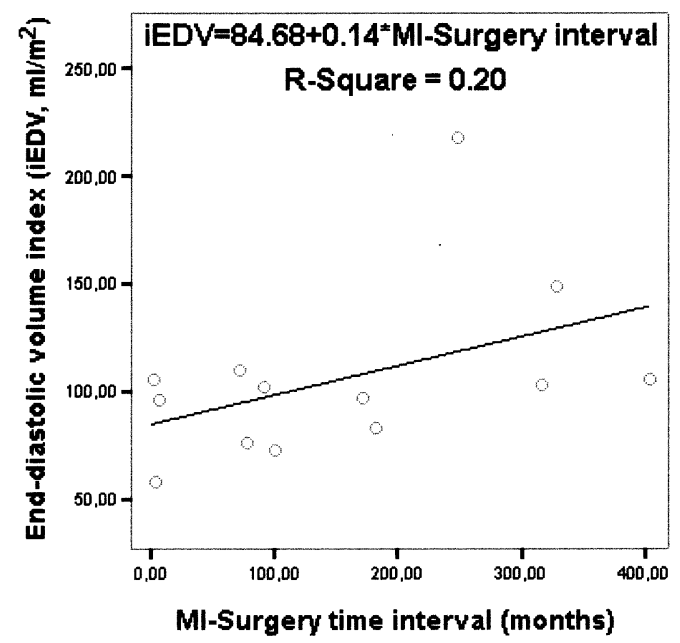

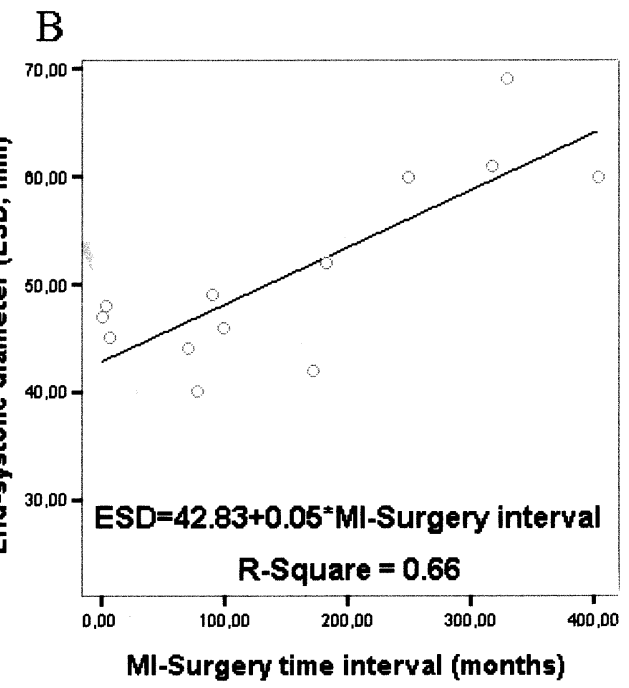

$\mathrm{D}$

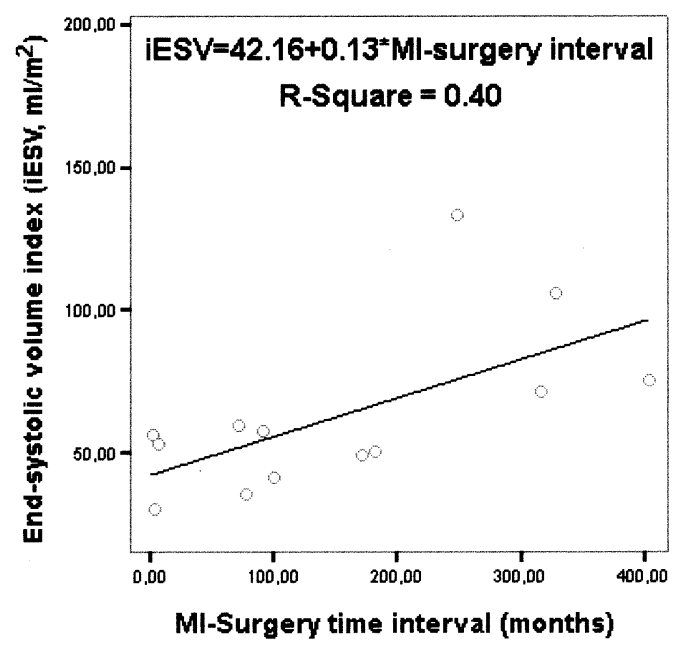

Figure 1. Scatter graphs showing linear regression between preoperative parameters and MI surgery time interval in posterior Mls.

operation (the first in the combined surgery group and the second in the mitral surgery group) and 3 noncardiac deaths ( 2 neoplasms and 1 cerebral accident). The mean New York Heart Association (NYHA) class of the 61 survivors is 1.4 \pm 0.6 : the mean $\mathrm{iESV}$ is $41.9 \mathrm{~mL} / \mathrm{m}^{2}$ in 20 patients in NYHA class $\geq 2$ and $34.1 \mathrm{~mL} / \mathrm{m}^{2}$ in 41 patients in NYHA class 1.

The actuarial survival of the entire series (Figure 2,A), including hospital and late cardiac-related deaths, was $90.1 \%$. The effects on group survival of the preoperative covariates considered in the analysis are shown in Figure 2 $(B, C$, and $D)$. The patients with an MI surgery time interval of $>60$ months showed a lower rate of survival, but this difference was not statistically significant despite the fact that the mean MI surgery time interval was $184.8 \pm 138.5$ months in the deceased patients versus $73.8 \pm 94.0$ months in the survivors $(P=.01)$. Survival 4 years postoperatively was significantly less in the patients with posterior versus anterior MI and in those undergoing mitral versus nonmitral surgery.

\section{Postoperative LV Geometric and Functional Parameters}

In the series as a whole, there was a significant improvement in all of the LV geometric and functional parameters. In particular, the mean reduction in end-systolic volume index was $42.7 \%$, and $71 \%$ of the patients showed a "normalized" $\operatorname{iESV}\left(\leq 40 \mathrm{~mL} / \mathrm{m}^{2}\right)$. The results are shown in Table 4 . 
A

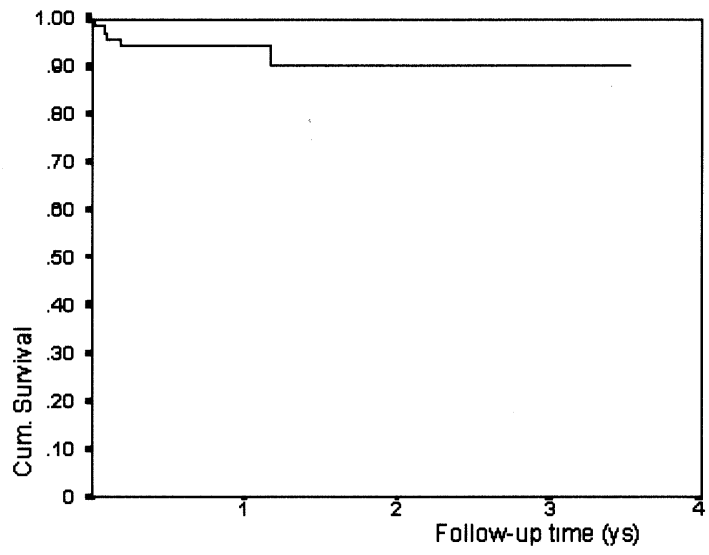

C

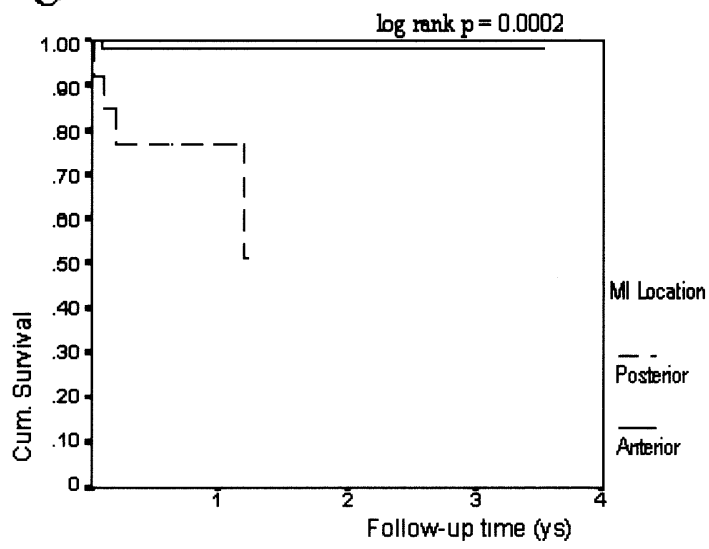

B
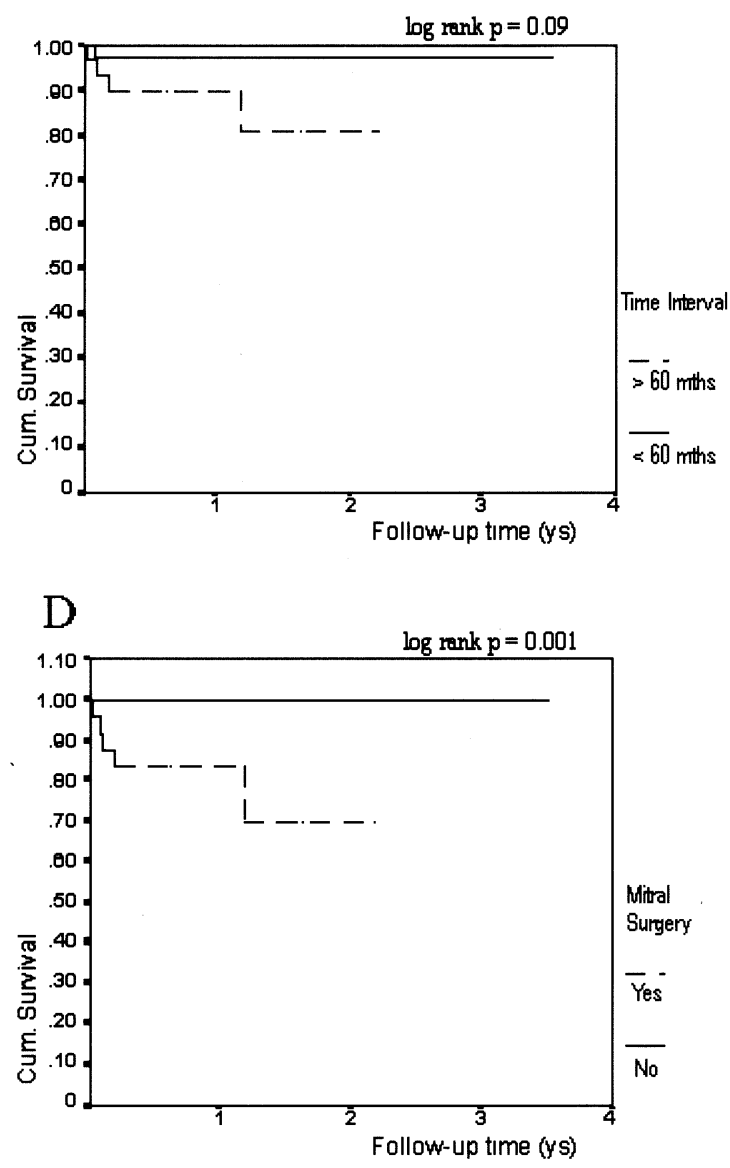

Figure 2. Kaplan-Meier survival curves for the patients as a whole (A) and the subgroups (B: MI surgery time interval; C: MI location; D: mitral surgery). Intergroup comparisons was made using the log-rank pairwise test.

In the group of posterior MI patients, the only parameters that significantly improved were end-diastolic volume $(P=$ $.004)$ and its indexed value $(P=.01)$. Comparison of the postoperative parameters in the anterior versus posterior MI group revealed significant differences in end-systolic diameter $(P=.003)$, systolic $(P=.001)$ and diastolic longitudinal length $(P=.000)$, end-diastolic volume $(P=.004)$, end-diastolic volume index $(P=.01)$, end-systolic volume $(P=.01)$, end-systolic volume index $(P=.001)$, and $\mathrm{EF}(P$ $=.000$; Table 2).

In the group of patients with an MI surgery time interval of $>60$ months, no improvement was observed in endsystolic and end-diastolic diameters or the percentage of akinesia. Comparison of the postoperative parameters in patients with an MI surgery time interval of $<60$ versus those $>60$ months revealed significant differences in all values except for systolic and diastolic eccentricity indexes (Table 3).

The patients undergoing mitral surgery showed no improvement in systolic and diastolic diameters or in the percentage of akinesia. Comparison of the postoperative parameters in the mitral versus nonmitral surgery groups revealed significant differences in all values except for systolic and diastolic eccentricity index, WMSI, and the percentage of akinesia (Table 5).

\section{Discussion}

Post-MI LV remodeling is a continuous process that worsens over time and depends on the location of the first MI episode. Thus, time from MI has to be considered a pathogenetic factor in the postischemic remodeling process. Time lapse also worsens the synchrony of neighboring regions even after the acute phase of MI by extending the necrosis and/or not preventing late apoptotic cell death in the border zone. ${ }^{15}$

Until now, no clinical studies have had over 2 years of follow-up time to measure the remodeling phenomenon. The TOAT study ${ }^{16}$ demonstrated an increase in LV volumes during the first year following MI. The 2-year SAVE 
TABLE 4. Comparison of preoperative and postoperative geometric and functional echocardiographic parameters in the patients as a whole

\begin{tabular}{lccc}
\hline Parameters & $\begin{array}{c}\text { Preoperative } \\
(\mathbf{n}=69)\end{array}$ & $\begin{array}{c}\text { Postoperative } \\
(\mathbf{n}=65)\end{array}$ & $\boldsymbol{P}$ value \\
\hline End-systolic diameter & $47.1 \pm 10.2$ & $42.7 \pm 7.7$ & $<.0001$ \\
End-diastolic diameter & $61.6 \pm 9.1$ & $55.5 \pm 7.4$ & $<.0001$ \\
Eccentricity index & & & \\
$\quad$ Systolic & $0.80 \pm 0.09$ & $0.72 \pm 0.13$ & $<.0001$ \\
$\quad$ Diastolic & $0.72 \pm 0.09$ & $0.58 \pm 0.17$ & $<.0001$ \\
Longitudinal length & & & \\
$\quad$ Systolic & $83.7 \pm 12.7$ & $65.3 \pm 10.1$ & $<.0001$ \\
$\quad$ Diastolic & $92.7 \pm 11.5$ & $73.8 \pm 9$ & $<.0001$ \\
End-diastolic volume & $186.8 \pm 70.1$ & $123.3 \pm 37.03$ & $<.0001$ \\
End-diastolic volume & $102 \pm 38.1$ & $67.03 \pm 17.8$ & $<.0001$ \\
$\quad$ index & & & \\
End-systolic volume & $120.3 \pm 53.5$ & $69.6 \pm 24.7$ & $<.0001$ \\
End-systolic volume index & $65.8 \pm 29.8$ & $37.7 \pm 12$ & $<.0001$ \\
Ejection fraction & $32.2 \pm 4.4$ & $44.8 \pm 7.8$ & $<.0001$ \\
Wall motion score index & $2.04 \pm 0.35$ & $1.68 \pm 0.25$ & $<.0001$ \\
\% of akinesia & $34.4 \pm 10.5$ & $28.6 \pm 7.5$ & $<.0001$ \\
\hline Parmetes are & & &
\end{tabular}

Parameters are defined in the Appendix.

study $^{3}$ demonstrated progressive LV dilation associated with chamber distortion and functional deterioration that was unaffected by captopril after 1 year; it also showed that the number of patients with LV dilation increased between the first and second post-MI year. The MI surgery time intervals in our patients varied widely, thus making it possible for us to study the phenomenon of remodeling over periods up to many years after the first episode.

The site of MI is another important factor that determines different remodeling pictures. Large anterior infarctions compromise LV torsion movement, which is the fundamental mechanism "squeezing" the LV cavity and causing ejection, ${ }^{17,18}$ more rapidly than posterior infarctions, and thus can lead to earlier important geometric alterations and heart failure. Posterior MI likely produces dysfunction of the posterior papillary muscle and/or posterior wall motion abnormalities, ${ }^{19,20}$ causing MR and consequent slowly progressive LV dilation. All these factors, variously overlapped, produce LV morphofunctional abnormalities leading to heart failure.

Our results show the effects of the time interval and MI site on hemodynamic and clinical status. In the population as a whole, systolic and diastolic diameters and diastolic eccentricity index were worse in the patients in whom the MI surgery interval was $>60$ months (Table 3). In the patients with posterior MI, time significantly affected LV dilation in terms of end-systolic and end-diastolic diameters and end-systolic and end-diastolic volume indexes (Figure 1), whereas the time interval was significantly less in the patients with anterior MI.

The majority of patients requiring mitral surgery had an MI surgery time interval of $>60$ months $(125 \pm 116.3$ months vs $58.8 \pm 84$ months in the nonmitral surgery group; $P=.008$ ). Furthermore, the presence of severe MR in the anterior MI group was time-related, as the mean MI surgery time interval in the patients with and without MR was, respectively, 108.9 versus 58.9 months $(P=.05)$.

Our study evidences also how the same factors able to condition LV remodeling can affect surgical outcome in terms of clinical results and geometrical restoration. A longer MI surgery time interval, posterior MI, and the need for mitral surgery all adversely affected clinical and geometric outcomes. All of our posterior MI patients with an MI surgery time interval of $>60$ months and mitral surgery experienced a complicated postoperative course, and all of the cardiac-related deaths occurred in mitral surgery patients. The MI surgery time interval was 104.7 months in patients in postoperative NYHA class $\geq 2$ versus 58.2 months in those in NYHA class $1(P=.02)$. Four of the 9 survivors with posterior MI (44.4\%) and 9 of the 16 survivors undergoing mitral surgery $(56 \%)$ are in NYHA class $\geq 2$.

In conclusion, our data suggest that time can represent an important factor affecting LV remodeling, so that it allows a worse dilation and the consequential development of MR and the sphericity of the heart. These factors can limit surgical technical possibilities to restore the left ventricle to physiological shape and/or require associated surgical procedures, affecting clinical outcome. Patients who experienced an MI need a strict follow-up to monitor LV shape and function. The presence and/or the development of an MR, a negative shape remodeling stated by volumes and diameters, and an increase in percentage of hypokinesiaakinesia must be promptly addressed and can represent an earlier surgical indication criterion.

\section{Study Limitations}

The small number of patients in the isolated mitral and combined surgery groups limits intergroup comparisons although the obtained significance is very high. The few fatal events do not allow a multivariate analysis of mortality. The medium-term and widely spread duration of follow-up may mask postoperative LV remodeling, which should be studied at longer time intervals.

\section{Clinical Implications}

In cardiomyopathies related to anterior MIs, the efficacy of Dor's operation and its modifications in the treatment of systolic dysfunction and ventricular dilation has by now been established ${ }^{21,22}$ and confirmed by our results. LV restoration surgery is limited by 3 factors: (1) the technical procedures proposed as a means of correcting posterior wall dysfunction are still unproven ${ }^{23,24}$; (2) it is possible to restore LV geometry but not myocardial architecture; and (3) surgical outcomes are strictly related to LV volume and 
TABLE 5. Comparison of geometric and functional echocardiographic parameters in patients without and with mitral surgery (repair or replacement)

\begin{tabular}{|c|c|c|c|c|}
\hline \multirow[b]{3}{*}{ Parameters } & \multicolumn{4}{|c|}{ Mitral surgery } \\
\hline & \multicolumn{2}{|c|}{ Preoperative } & \multicolumn{2}{|c|}{ Postoperative } \\
\hline & $\begin{array}{c}\text { No } \\
\text { (n = 45) }\end{array}$ & $\begin{array}{c}\text { Yes } \\
(n=24)\end{array}$ & $\begin{array}{c}\text { No } \\
\text { (n }=45)\end{array}$ & $\begin{array}{c}\text { Yes } \\
(n=20)\end{array}$ \\
\hline End-systolic diameter & $46.4 \pm 10.7$ & $48.5 \pm 9.16$ & $40.6 \pm 7.0 \dagger$ & $46.7 \pm 7.6^{*}$ \\
\hline $\begin{array}{l}\text { End-diastolic diameter } \\
\text { Eccentricity index }\end{array}$ & $60.9 \pm 9.3$ & $62.9 \pm 8.9$ & $56.4 \pm 6.9 \dagger$ & $59.6 \pm 7.9$ \\
\hline Systolic & $0.82 \pm 0.09$ & $0.78 \pm 0.08$ & $0.73 \pm 0.12 \dagger$ & $0.71 \pm 0.14 \dagger$ \\
\hline Diastolic & $0.74 \pm 0.09$ & $0.70 \pm 0.09$ & $0.57 \pm 0.16 \dagger$ & $0.59 \pm 0.20 \dagger$ \\
\hline \multicolumn{5}{|l|}{ Longitudinal length } \\
\hline Systolic & $84.6 \pm 11.8$ & $81.9 \pm 14.4$ & $62.4 \pm 7.3 \dagger$ & $70.8 \pm 12.3^{*}, \dagger$ \\
\hline Diastolic & $93.9 \pm 11.6$ & $90.2 \pm 11.2$ & $71.3 \pm 6.8 \dagger$ & $78.6 \pm 10.6^{*}, \dagger$ \\
\hline End-diastolic volume & $183.3 \pm 73.7$ & $193.5 \pm 63.6$ & $113.4 \pm 31.8 \dagger$ & $141.7 \pm 39.6^{*}, \dagger$ \\
\hline End-diastolic volume index & $100.3 \pm 40.5$ & $105.1 \pm 33.8$ & $62.2 \pm 16.3 \dagger$ & $76.1 \pm 17.3^{*}, \dagger$ \\
\hline End-systolic volume & $119.7 \pm 57.1$ & $121.4 \pm 47.4$ & $61.6 \pm 14.7 \dagger$ & $84.6 \pm 32.2^{*}, \dagger$ \\
\hline End-systolic volume index & $65.7 \pm 32.1$ & $66.1 \pm 25.6$ & $33.7 \pm 7.7 \dagger$ & $45.2 \pm 14.9^{*}, \dagger$ \\
\hline Ejection fraction & $32.6 \pm 3.8$ & $32.1 \pm 4.8$ & $47.9 \pm 5.7 \dagger$ & $39.1 \pm 8.1^{*}, \dagger$ \\
\hline Wall motion score index & $2.1 \pm 0.3$ & $2.1 \pm 0.3$ & $1.6 \pm 0.21 \dagger$ & $1.7 \pm 0.31 \dagger$ \\
\hline$\%$ of akinesia & $34.9 \pm 9.1$ & $33.6 \pm 13.1$ & $27.4 \pm 4.8 \dagger$ & $30.7 \pm 10.7$ \\
\hline
\end{tabular}

Parameters are defined in the Appendix.

*Significance between the groups, nonmitral surgery versus mitral surgery performed.

tSignificance within the group, preoperative versus postoperative.

the need for mitral procedures. ${ }^{25}$ Geometric remodeling and clinical results stratified by the preoperative covariates identified in our experience can help establish the correct timing for the surgical treatment of ischemic cardiomyopathy.

In patients with late presentation, surgery is still indicated even with higher risk and lower "restitutio ad integrum" possibility.

Statistical analysis of a larger series of patients could identify the power of risk factors in the preoperative stratification of patients. It is necessary to test further surgical techniques of reversing geometric changes in the mitral valve complex.

\section{References}

1. Francis J, Weiss RM, Wei SG, Johnson AK, Felder RB. Progression of heart failure after myocardial infarction in the rat. Am J Physiol Regul Integr Comp Physiol. 2001;281:R1734-45.

2. Zimmerman SD, Karlon WJ, Holmes JW, Omens JO, Covell JW Structural and mechanical factors influencing infarct scar collagen organization. Am J Physiol Heart Circ Physiol. 2000;278:H194-200.

3. St John Sutton M, Pfeffer MA, Moye L, Plappert T, Rouleau JL, Lamas G, et al. Cardiovascular death and left ventricular remodeling two years after myocardial infarction: baseline predictors and impact of long-term use of captopril: information from the Survival and Ventricular Enlargement (SAVE) trial. Circulation. 1997;96:3294-9.

4. St John Sutton M, Sharpe N. Left ventricular remodeling after myocardial infarction. Pathophysiology and therapy. Circulation. 2000; 101:2981-8.

5. Mann DL. Mechanisms and models in heart failure. A combinatorial approach. Circulation. 1999;100:999-1008.

6. Gorman JH, Gorman RC, Plappert T, Jackson B, Hiramatsu Y, JohnSutton MG, et al. Infarct size and location determine development of mitral regurgitation in the sheep model. J Thorac Cardiovasc Surg. 1998;115:615-22.

7. Tibayan FA, Lai DT, Timek TA, Dagum P, Liang D, Zasio MK, et al. Alterations in left ventricular curvature and principal strains in dilated cardiomyopathy with functional mitral regurgitation. $J$ Heart Valve Dis. 2003;12:292-9.

8. Buckberg G. Congestive heart failure: treat the disease, not the symptom-return to normalcy. J Thorac Cardiovasc Surg. 2001;121:62837

9. White HD, Norris RM, Brown MA, Brandt PW, Whitlock RM, Wild CJ. Left ventricular end-systolic volume as the major determinant of survival after recovery from myocardial infarction. Circulation. 1987; 76:44-51.

10. Migrino RQ, Young JB, Ellis SG, White HD, Lundergan CF, Miller $\mathrm{DP}$, et al. End-systolic volume index at 90 to 180 minutes into reperfusion therapy for acute myocardial infarction is a strong predictor of early and late mortality. The Global Utilization of Streptokinase and t-PA for Occluded Coronary Arteries (GUSTO)-I Angiographic Investigators. Circulation. 1997;96:116-21.

11. Di Donato M, Toso A, Maioli M, Sabatier M, Stanley AWH, Dor V. Intermediate survival and predictors of death after surgical ventricular restoration. Semin Thorac Cardiovasc Surg. 2001;13:468-75.

12. Yamaguchi A, Ino T, Adachi $\mathrm{H}$, et al. Left ventricular volume predicts postoperative course in patients with ischemic cardiomyopathy. Ann Thorac Surg. 1998;65:434-8.

13. Burch GE, Tsui CY, Harb JM. Ischemic cardiomyopathy. Am Heart J. 1972;83:340-50

14. Dor V, Kreitmann P, Jourdan J. Interest of "physiological" closure (circumferential plasty on contractile areas) of left ventricle after resection and endocardectomy for aneurysm or akinetic zone: comparison with classical technique of about 209 left ventricular resections [abstract]. J Cardiovasc Surg. 1985;26:73.

15. Olivetti G, Abbi R, Quaini F, Kajstura J, Cheng W, Nitahara JA, et al. Apoptosis in the failing human heart. N Engl J Med. 1997;336:113141.

16. Yousef ZR, Redwood SR, Bucknall CA, Sulke AN, Marber MS. Late 
intervention after anterior myocardial infarction: effects on left ventricular size, function, quality of life and exercise tolerance. $J$ Am Coll Cardiol. 2002;40:869-76.

17. Ingels Neil B. Myocardial fiber architecture and left ventricular function. Technol Health Care. 1997;5:45-52.

18. Spotnitz HM. Macro design, structure, and mechanics of the left ventricle. J Thorac Cardiovasc Surg. 2000;119:1053-77.

19. Kumanohoso T, Otsuji Y, Yoshifuku S, Koriyama C, Kisanuki A, Minagoe S, et al. Mechanism of higher incidence of ischemic mitral regurgitation in patients with inferior myocardial infarction: quantitative analysis of left ventricular and mitral valve geometry in 103 patients with prior myocardial infarction. $J$ Thorac Cardiovasc Surg. 2003;125:135-43.

20. Liel-Cohen N, Guerrero L, Otsuji Y, Handschumacher MD, Rudski LG, Unziker PR, et al. Design of a new surgical approach for ventricular remodelling to relieve ischemic mitral regurgitation. Circulation. 2000;101:2756-63.

21. Athanasuleas CL, Stanley AWH Jr, Buckberg GD, Dor V, Di Donato $\mathrm{M}$, Blackstone EH, the RESTORE Group. Surgical anterior ventricular endocardial restoration (SAVER) in the dilated remodelled ventricle after anterior myocardial infarction. J Am Coll Cardiol. 2001;37:1199209.

22. Kelley ST, Malekan R, Gorman JH III, Jackson BM, Gorman RC, Suzuki Y, et al. Restraining infarct expansion preserves left ventricular geometry and function after acute anteroapical infarction. Circulation. 1999;99:135-42.

23. Nair RU, Williams SG, Nwafor UK, Hall AS, Tan L. Left ventricular volume reduction without ventriculectomy. Ann Thorac Surg. 2001; 71:2046-9

24. Raman J, Dixit A, Storer M, Hare D, Buxton BF. Geometric endoventricular patch repair of inferior left ventricular scars improves mitral regurgitation and clinical outcome. Ann Thorac Surg. 2001;72: S1055-8.

25. Di Donato M, Sabatier M, Dor V, Genuini GF, Toso A, Maioli M, et al. Effects of the Dor procedure on left ventricular dimension and shape and geometric correlates of mitral regurgitation one year after surgery. J Thorac Cardiovasc Surg. 2001;121:91-6.

26. Schiller NB. Recommendation for quantification of the left ventricle by two-dimensional echocardiography. J Am Soc Echocardiogr. 1989; 5:358-67.

APPENDIX. Echocardiographic geometric and functional parameters: definitions and abbreviations

Equatorial diameter (systolic and diastolic)

Eccentricity index (systolic and diastolic) ${ }^{8}$

Longitudinal length (systolic and diastolic)

End-systolic and end-diastolic left ventricular volume

End-systolic and end-diastolic left ventricular volume index

Ejection fraction

Wall motion score index

Percentage of akinesia
ESD, EDD, mm

Four-chamber apical view, orthogonally crossing the $L L$ at the widest level

$\mathrm{EIS}, \mathrm{EID}=\sqrt{\mathrm{LL}^{2}-\mathrm{ED}^{2} / \mathrm{LL}}$

LS, LD, mm

Four-chamber apical view, from mitral valve level to the furthest point of the apex

ESV, EDV, $\mathrm{mL}$

Simpson's biplane method

iESV, iEDV, $\mathrm{mL} / \mathrm{m}^{2}$

Simpson's biplane method

$\mathrm{EF}, \%$

Simpson's biplane method

WMSI, numerical

Mean score in a 16-segment model of the left ventricle, according to Schiller ${ }^{26}$

AKIN, \%

Percentage of akinetic segments 